activity. In the present case, however, the inhibitory activity was more probably of maternal origin since six exchanges (total of 24 litres) were required to remove it.

We have recently undertaken plasma exchanges on several other women sensitised to anti-D with disappointing results, despite using a more intensive regimen than that reported to be successful elsewhere. ${ }^{2}$ Our present findings suggest that the role of plasma exchange in haemolytic disease of the newborn is more complex than simply removing the antibody and that further investigations are required.

We thank Dr John Scrimgeour for permission to publish details of this patient, the staff of the cell separator unit for providing samples, and the antenatal laboratory staff for measuring anti-D concentrations.

\section{References \\ ${ }^{1}$ Clarke CA, Elson CJ, Bradley J, Donohoe WTA, Lehane D, Hughes- Jones NC. Intensive plasmapheresis as a therapeutic measure in rhesus-immunised women. Lancet 1970; i:793-8. \\ ${ }^{2}$ Fraser ID, Bothamley JE, Bennet MO, et al. Intensive antenatal plasma- pheresis in severe rhesus isoimmunisation. Lancet $1976 ; \mathrm{i}: 6-8$.}

${ }^{3}$ Powell LC Jr. Intense plasmapheresis in the pregnant Rh-sensitized woman. Am $\mathcal{F}$ Obstet Gynecol 1968;101:153-70.

4 Graham-Pole JR, Barr W, Willoughby MLN. Continuous-flow exchangeplasmapheresis in severe rhesus isoimmunisation. Lancet 1974;i:1051.

5 Gunson HH, Phillips PK, Stratton F. Manipulative and inherent errors in anti-D quantitation using the AutoAnalyzer. $\mathcal{F}$ Clin Pathol 1972;25: 198-205.

${ }^{6}$ Urbaniak SJ. ADCC (K-cell) lysis of human erythrocytes sensitized with rhesus alloantibodies. I. Investigation of in vitro culture variables. Br F Haematol 1979;42:303-14.

${ }^{7}$ Urbaniak SJ, White AG, Barclay GR, Wood SM, Kay AB. Tests of immune function. In: Weir, DM, ed. Handbook of experimental immunology. 3rd ed. Edinburgh: Blackwell, 1978.

${ }^{8}$ Urbaniak SJ. Studies on human K-cell haemolysis. PhD thesis. Edinburgh, December 1977.

9 Isbister JP, Ting A, Seeto KM. Development of Rh-specific maternal autoantibodies following intensive plasmapheresis for $\mathrm{Rh}$ immunisation during pregnancy. Vox Sang 1977;33:353-8.

10 Branda RF, Moldow CF, McCullough JJ, Jacob HS. Plasma exchange in the treatment of immune disease. Transfusion 1975;15:570-6.

${ }^{11}$ Koros AMC, Hamill EC, Depp OR. Anti-autologous erythrocyte plaqueforming cells in pregnancy: a parameter of immunoregulatory change. Vox Sang 1978;35:277-87.

\section{Summary and conclusions}

Platelets from eight patients thought clinically to have deep venous thrombosis were labelled with indium-111 and reinjected. Subsequent scanning of the patients with a wholebody scanner and imaging with a gammacamera showed focal accumulation of the label at five sites in four legs, which correlated precisely with the sites of venous thrombi identified by ascending venography.

This technique is a useful addition to methods for diagnosing venous thrombosis.

\section{Introduction}

Many techniques are used for detecting leg-vein thrombosis. ${ }^{1}$ Ascending venography is the yardstick by which all others are measured but it is often uncomfortable and carries a small but definite morbidity. ${ }^{2}{ }^{3}$ The use of fibrinogen labelled with iodine- 125 avoids the problem of discomfort and has the major advantage of being performed at the bedside. It has two major disadvantages, however. Firstly, though accuracy is good in detecting calf-vein thrombosis it diminishes in the thigh, ${ }^{1}$ and the method is useless for detecting pelvic-vein thrombosis; secondly, its value lies in detecting thrombi as they form, whereas it does not accurately identify already established thrombi.

University of Aberdeen, Foresterhill, Aberdeen AB9 2ZD

ALBERT FENECH, MD, MRCP, lecturer in medicine

P P DENDY, PHD, senior lecturer, department of biomedical physics and bioengineering

J K HUSSEY, MB, DMRD, senior registrar, department of radiology

B BENNETT, MRCP, MRCPATH, senior lecturer in medicine

A S DOUGLAS, FRCP, FRCPATH, regius professor of medicine
Platelets labelled with indium-111 have been used to estimate platelet survival, ${ }^{4-7}$ to diagnose renal transplant rejection, ${ }^{8}$ and in attempts to detect atherosclerotic plaques. ${ }^{\circ 10}$

This study was undertaken to determine whether platelets labelled with this radionuclide were useful in detecting established venous thrombosis.

\section{Materials and methods}

Platelets were labelled with indium-111 by the method of Hawker et al. ${ }^{711}$ A total of $26 \mathrm{ml}$ of venous blood was withdrawn with an 18-gauge needle, $9 \mathrm{ml}$ being added to $1 \mathrm{ml} \mathrm{3.8 \%} \mathrm{trisodium}$ citrate and used for aggregation standards and the production of platelet-poor plasma. The remaining $17 \mathrm{ml}$ was anticoagulated with $3 \mathrm{ml}$ acid citrate and the platelets separated by differential centrifugation, washed, resuspended in $\mathrm{Ca}^{++}$-free Tyrode's solution containing prostaglandin $\mathrm{E}_{1}$ (Imperial Chemical Industries Ltd), and incubated with $200-250 \mu \mathrm{Ci}$ indium-111 oxine (Radiochemical Centre) at $37^{\circ} \mathrm{C}$ for 60 seconds. After centrifugation the platelets were suspended in $5 \mathrm{ml}$ of platelet-poor plasma and reinjected into the patient 45-60 minutes after the initial venepuncture.

Scanning at slow speed was performed with an El-Scint wholebody scanner fitted with medium-energy VC-3 collimators, and the data were displayed on a VD2 videoprocessing colour display. Regions of interest were imaged with an Ohio Nuclear series 410 wide-fieldof-view gammacamera linked to a Digital Equipment Corporation Gamma-11 computer system.

Ascending venography was performed on all patients after scanning was completed and the findings reported without knowledge of the results of scanning.

\section{Results}

Eight patients were studied. Ascending venography was performed on 13 legs, and five thrombi were identified in four. The number, location, and extent of these correlated precisely with the areas in 
which abnormal accumulations of the radiolabel had been found when the scans were interpreted. Two representative cases are described.

Case 1-A 61-year-old retired publican admitted to hospital with a three-day history of haemoptysis and left-sided pleuritic chest pain subsequently developed a pleural rub. He had no symptoms or clinical signs in his legs. Chest radiographs and lung scans suggested a pulmonary embolus. Ten days after admission his platelets were labelled with $250 \mu \mathrm{Ci}$ indium-111; figure 1 shows the gammacamera views obtained 20 hours later. There was a major concentration of label in the left leg extending from the iliac to the popliteal vein; this corresponded to the thrombus detected by venography. The scan also suggested the presence of a small thrombus in the right iliac vein; the patient, however, found venography so uncomfortable that he declined to undergo venography of the right leg.

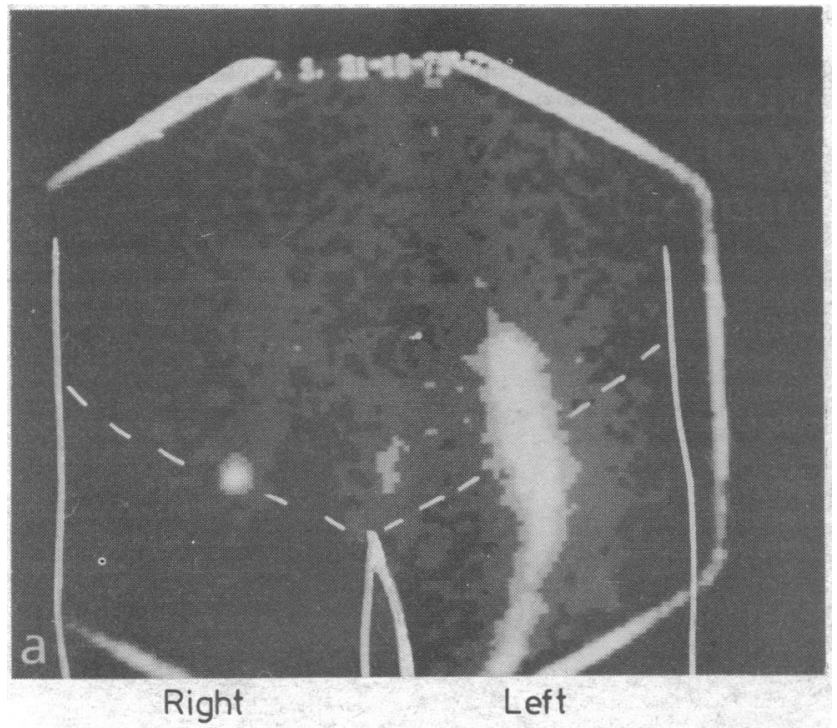

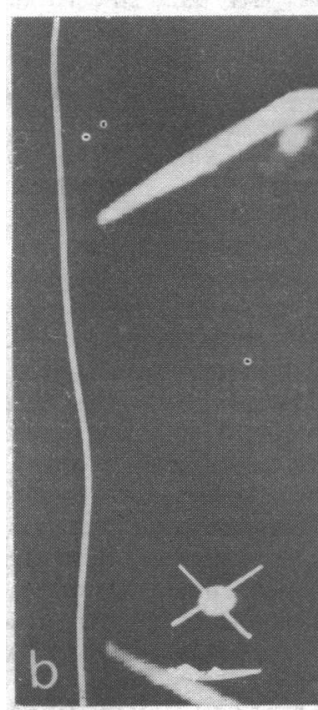

Right

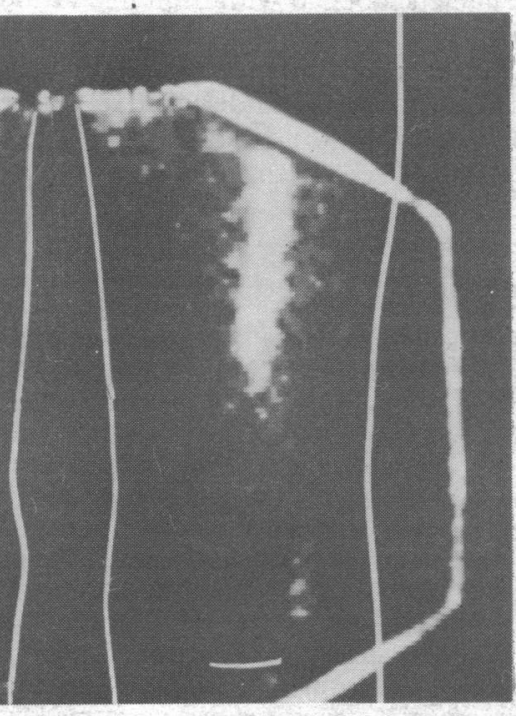

Left
FIG 1-Case 1. (a) Anterior scan of pelvis. (b) Anterior scan of thighs; marker shown over right knee.

Case 2-A 55-year-old woman undergoing routine ${ }^{125}$ I-fibrinogen scanning after a gynaecological operation developed a "hot spot" in her left calf four days after a Manchester repair. Her platelets were labelled with $200 \mu \mathrm{Ci}$ indium-111 three days later, and the scans obtained 24 hours after injection showed a major concentration of label in this calf, and suggested that a thrombus was present in the long saphenous vein close to the entry into the femoral vein (fig 2). Both the calf-vein thrombus and the saphenousvein thrombus were confirmed on venography.

No side effects were experienced by any of the patients studied.

\section{Discussion}

This technique offers several advantages over the use of ${ }^{125}$ I-fibrinogen. It identifies already established thrombi, and in our hands identified thrombi that on clinical grounds were believed to be up to five weeks old. It also identifies thrombi high in the iliofemoral segment. As mobile gammacameras become more widely available, imaging should be possible with
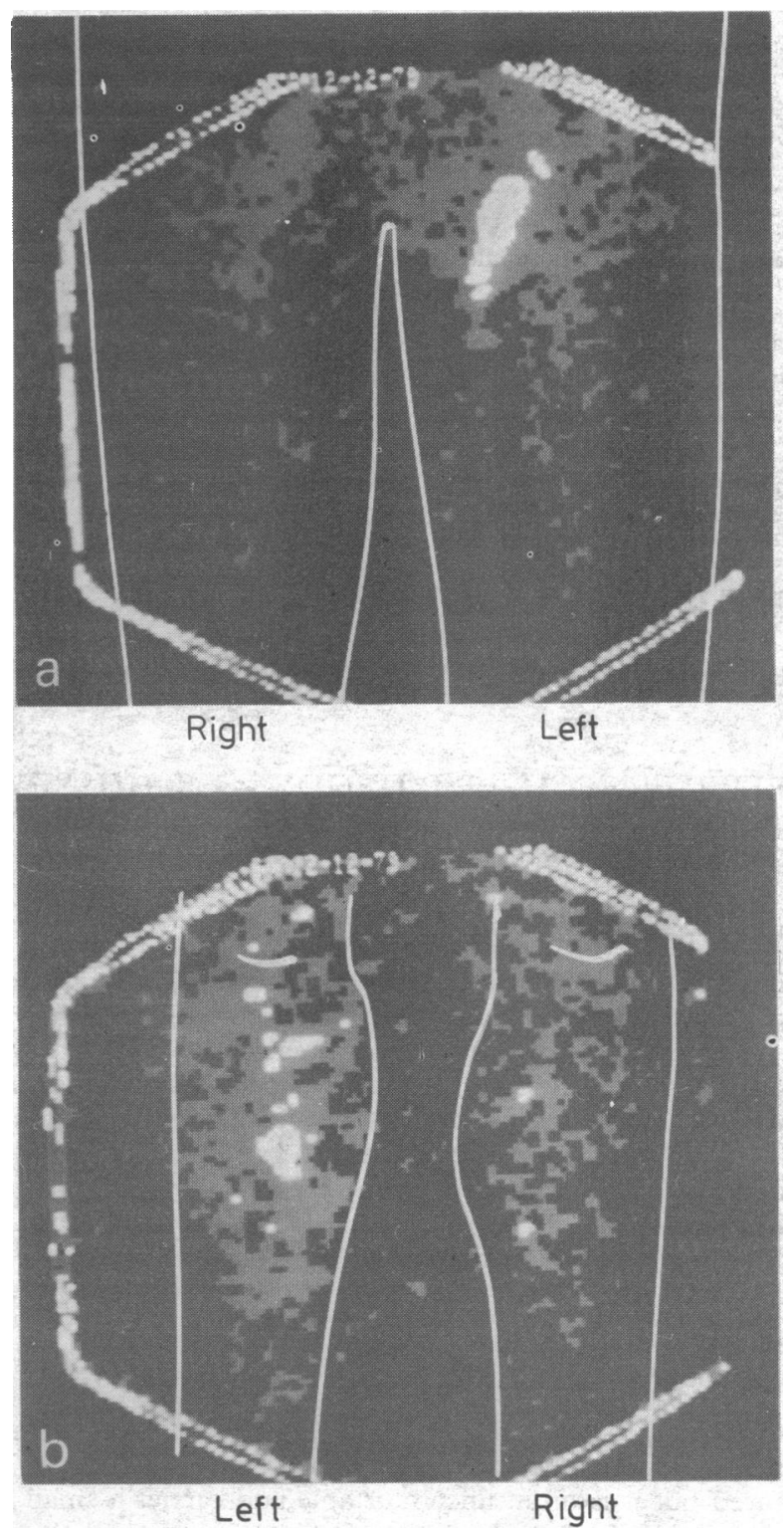

FIG 2-Case 2. (a) Anterior scan of thighs. (b) Posterior scan of calves.

minimal movement of the patient. The procedure is free of discomfort, which is an advantage over venography. The total dose of radiation to the spleen, which is the target organ in this examination, has been estimated as $4 \cdot 0-5 \cdot 5$ rads when the stated doses of indium-111 are used.

A detailed comparison of the accuracy of this technique with that of venography in identifying venous thrombi is currently under way. The results of this study suggest that this technique will be a valuable addition to methods for diagnosing leg-vein thrombosis.

We thank Dr D Abramovich and Dr $\mathrm{K}$ Toop for allowing us to study case 2, the Radiochemical Centre for supplying indium-111 oxine, and Imperial Chemical Industries for supplying prostaglandin 
$\mathrm{E}_{1}$. We are grateful to Joyce Davidson and Lesley Kemp for excellent technical help. Albert Fenech thanks Robert and Linda Hawker for their help and patience in teaching him their technique.

\section{References}

${ }^{1}$ Browse N. Diagnosis of deep vein thrombosis. Br Med Bull 1978;34:163-7.

${ }^{2}$ Hume M, Sevitt S, Thomas DP, eds. Venous thrombosis and pulmonary embolism. Cambridge, Massachusetts: Harvard University Press, 1970.

3 Madden JL, Hume M, eds. Venous thromboembolism. Prevention and treatment. New York: Apple-Century-Crofts, 1976

4 Heyus du Pont A, Lötter MG, Badenhorst PN, Van Reenen OR. ${ }^{111}$ Indiumlabelled human platelets: kinetics, distribution and sites of destruction. Thromb Haemostas 1979;42:18.

${ }^{5}$ Knudsen JB, Gormsen J. Studies on platelet survival time with ${ }^{111}$ indium. Thromb Haemostas 1979;42:19.
6 Hawker RJ, Hawker LM, Wilkinson AR. Use of indium-111 oxine to label human platelets. Lancet 1978;ii:483.

${ }^{7}$ Hawker RJ, Hawker LM. Optimal method and labelling parameters of indium ${ }^{111}$ human platelets. Thromb Haemostas 1979;42:18.

${ }^{8}$ Smith N, Chandler S, Hawker RJ, Hawker LM, Barnes AD. Indiumlabelled autologous platelets as diagnostic aid after renal transplantation. Lancet 1979;ii:1241-2.

- Davis HH, Heaton WA, Siegel BA, et al. Scintigraphic detection of atherosclerotic lesions and venous thrombi in man by indium-111labelled autologous platelets. Lancet 1978;i:1185-7.

${ }^{10}$ Davis HH, Heaton WA, Siegel BA, Joist JH, Welch MJ, Sherman LA. Utility of indium ${ }^{111}$ labelled platelet scans in assessing the dynamics of thrombovascular lesions. An experience with 70 patients. Thromb Haemostas 1979;42:328.

11 Hawker RJ, Hawker LM, Wilkinson AR. Indium(111 In)-labelled human platelets: optimal method. Clin Sci Mol Med 1980;58:243-8.

(Accepted 1 April 1980)

\title{
Atenolol, sustained-release oxprenolol, and long-acting propranolol in hypertension
}

\author{
J C PETRIE，T A JEFFERS， O J ROBB， A K SCOTT，J WEBSTER
}

\section{Summary and conclusions}

The effect of once-daily atenolol, sustained-release oxprenolol (a new formulation of oxprenolol presented as a compressed tablet in a waxed matrix), and longacting propranolol (a new formulation presented as spheroids in a capsule) was studied in a double-blind crossover trial in 23 carefully selected hypertensive outpatients. After a run-in period with matching placebo each patient received atenolol (100 mg/day), sustainedrelease oxprenolol (160 $\mathrm{mg} / \mathrm{day})$, long-acting propranolol (160 $\mathrm{mg} / \mathrm{day})$, and placebo according to a randomised sequence.

After four weeks' treatment with sustained-release oxprenolol blood pressure in the two to four hours before the next dose was not significantly lower than after placebo. The effectiveness of atenolol and of the new formulation of propranolol in reducing blood pressure was confirmed.

These results suggest that the present formulation of sustained-release oxprenolol should be reconsidered.

\section{Introduction}

We have compared conventional fixed doses of three betaadrenoceptor antagonists that are claimed to be suitable for once-daily use in hypertension-namely, atenolol, sustainedrelease oxprenolol (a compressed tablet in a waxed matrix), and long-acting propranolol (a spheroid formulation).

\footnotetext{
University Department of Therapeutics and Clinical Pharmacology, Aberdeen Royal Infirmary, Aberdeen AB9 2ZD

J C PETRIE, MRCP, senior lecturer

T A JEFFERS, MRCP, consultant physician

O J ROBB, MB, research fellow

A K SCOTT, MRCP, lecturer

J WEBSTER, MRCP, lecturer
}

\section{Patients and methods}

Our procedure for selecting patients with mild hypertension has been described. ${ }^{2}$ Patients were excluded if their lying diastolic pressure fell below $90 \mathrm{~mm} \mathrm{Hg}$ after a four-week outpatient run-in period with placebo. Suitable patients were then allocated in a randomised order to four treatment periods (double-blind, within-patient) of four weeks each.

Twenty-three patients were studied (12 men; average age 40.9 years, range 21-59). The drugs were taken once daily at 1800 , the doses (atenolol $100 \mathrm{mg}$, sustained-release oxprenolol $160 \mathrm{mg}$, longacting propranolol $160 \mathrm{mg}$, or matching placebo) being considered to be approximately equivalent in effect.

Blood pressures were recorded with Hawksley random-zero sphygmomanometers (diastolic pressure phase 4) under standard conditions. ${ }^{12}$ The means of two blood-pressure readings and heart rates were recorded after five minutes' lying and two minutes' standing. A single measurement of heart rate and blood pressure was taken immediately after a two-step exercise test designed to produce a target untreated heart rate of $140 / \mathrm{min} .^{2}$ Measurements were made between 1400 and 1630 (20-22 hours after dosing), at the same time of day on each occasion for each patient. Patients were seen fortnightly. A questionnaire on symptoms was completed by a different observer from the one recording blood pressure. ${ }^{12}$ Compliance with drug taking, assessed by tablet counts, was satisfactory throughout ( $>90 \%$ ).

Data on blood pressure, heart rate, and weight were analysed separately by analysis of variance after two and four weeks with each treatment. If the overall comparison between treatments, as assessed by the $\mathrm{F}$ test, was significant at the $5 \%$ level then pairs of adjusted means were compared using a $t$ test. The standard deviation used in the $t$ test was based on the residual mean square from the analysis of variance.

\section{Results}

Table I lists the mean blood pressures, pulse rates, and weights during the run-in and treatment periods, and table II the levels of statistical significance.

After four weeks' treatment systolic and diastolic blood pressures measured lying, standing, and after exercise were significantly lower after atenolol and long-acting propranolol than after placebo, but the same was not true for sustained-release oxprenolol. Atenolol was significantly superior to sustained-release oxprenolol after four weeks' treatment in lowering systolic and diastolic blood pressures and heart rates in each position. Long-acting propranolol was also superior to 